\title{
Correction to: Early Colorectal Cancer Detected by Machine Learning Model Using Gender, Age, and Complete Blood Count Data
}

\author{
Mark C. Hornbrook ${ }^{1}$ (D) Ran Goshen ${ }^{2} \cdot$ Eran Choman $^{2} \cdot$ Maureen O'Keeffe-Rosetti $^{1}$ Yaron Kinar $^{2,3} \cdot$ \\ Elizabeth G. Liles ${ }^{1} \cdot$ Kristal C. Rust $^{1,4}$
}

Published online: 27 November 2017

(c) The Author(s) 2017

\section{Correction to: \\ Dig Dis Sci (2017) 62:2719-2727 \\ https://doi.org/10.1007/s10620-017-4722-8}

The article Early Colorectal Cancer Detected by Machine Learning Model Using Gender, Age, and Complete Blood Count Data, written by Mark C. Hornbrook, Ran Goshen, Eran Choman, Maureen O'Keeffe-Rosetti, Yaron Kinar, Elizabeth G. Liles, and Kristal C. Rust, was originally published Online First without open access. After publication in volume 62, issue 10, page 2719-2727 the author decided to opt for Open Choice and to make the article an open access publication. Therefore, the copyright of the article has been changed to (C) The Author(s) [2017] and the article is forthwith distributed under the terms of the Creative Commons Attribution Attribution-NonCommercial 4.0 International License (http://creativecommons.org/ licenses/by-nc/4.0/), which permits any noncommercial use, duplication, adaptation, distribution, and reproduction in any medium or format, as long as you give appropriate credit to the original author(s) and the source, a link is provided to the Creative Commons license and any changes made are indicated.
The original article can be found online at https:// doi.org/10.1007/s10620-017-4722-8.

Mark C. Hornbrook

mark.c.hornbrook@gmail.com

Ran Goshen

ran@earlysign.com

Eran Choman

eran@earlysign.com

Maureen O'Keeffe-Rosetti

maureen.rosetti@kpchr.org

Yaron Kinar

yaron@medial-research.com

Elizabeth G. Liles

Elizabeth.G.Liles@kp.org

Kristal C. Rust

kristal.c.rust@kp.org

1 Kaiser Permanente Center for Health Research, 3800 North Interstate Avenue, Portland, OR 97227-1110, USA

2 Medial EarlySign Inc., 11 HaZait St., Kfar Malal, Israel

3 Medial Research, Inc., 11 HaZait St., Kfar Malal, Israel

4 Kaiser Sunnyside Medical Center, LL Nursing Administration, 10180 SE Sunnyside Road, Clackamas, OR 97015, USA 